\title{
Neuroprotective effects of Lepidium sativum L. on memory impairments in Wistar rat: Behavioral and neurochemical study
}

\author{
Soumia Ed-Day ${ }^{1}$, Samira Boulbaroud ${ }^{2}$, Latifa Didou ${ }^{1}$, Radia Elgui ${ }^{1}$, Ahmed Ahami ${ }^{1}$ and Fatima-Zahra Azzaoui ${ }^{1}$. \\ ${ }^{1}$ Biology and Health Laboratory, Department of Biology, Faculty of Science, Ibn Tofail University, PoBox.133, Kenitra, \\ Morocco. \\ ${ }^{2}$ Polydisciplinary Faculty, Sultan Moulay Slimane University, Beni Mellal, Morocco.
}

\begin{abstract}
The present study investigated the effect of Lepidium sativum L. on Memory and on Acetylcholinesterase (AChE) activity in different brain structures among cadmium-exposed rats. Animals were divided into three groups: Control group (T): received a distilled water orally, Cadmium group (Cd): received oral administration dose of Cadmium Chloride $\left(\mathrm{CdCl}_{2}\right)$ at $10 \mathrm{mg} / \mathrm{kg}$, Protective group (Cd/LS): received $\mathrm{CdCl}_{2}(10 \mathrm{mg} / \mathrm{kg})$ and the aqueous extract of Lepidium sativum L. $(20 \mathrm{mg} / \mathrm{kg})$ orally. The Novel Object Recognition Memory Test is used to evaluate the short and long term memory. The measure of AchE activity is realized by Ellman's method. The results showed that subchronic Cadmium Chloride intoxication at a dose of $10 \mathrm{mg} / \mathrm{kg}$ caused a neurobehavioral impairments including: A significant decrease in the index of recognition of short-term $(\mathrm{p}<0.01)$ and long-term memory $(\mathrm{p}<0.05)$ compared to the control group. In addition, this index increase in the group $(\mathrm{Cd} / \mathrm{LS})$ compared to the group intoxicated by $\mathrm{CdCl}_{2}$. A highly significant increase in the enzymatic activity of acetylcholinesterase in hippocampus, cerebellum, and cortex $(p<0.001)$ is registered. These results indicate that the aqueous extract of Lepidium sativum $L$. may modulate the toxic effect induced by cadmium and consequently improve cognition.
\end{abstract}

\section{Introduction}

Lepidium sativum Linn (Garden cress, Brassicaceae) is an annual herb used to treat a number of illness in traditional medicine. The plant ethno-medical uses mainly focused on its anti-inflammatory, antipyretic, analgesic, coagulant, antihypertensive, diuretic, anti-diabetic, hepatoprotective, anti-asthmatic, prokinetic, laxative, hypercholesterolemic, fracture healing, chemo-protective and anti-oxidant activities. This plant mainly contains alkaloids, saponins, anthracene glycosides, carbohydrates, proteins, amino acids, flavonoids, sterols. Also it contains carotene, cellulose, calcium, phosphorus, iron, thiamine, riboflavin, niacin, uric acid [1]. The plants as Lepidium sativum $L$. rich in essential metals and minerals play an important role in prevention and alleviation of heavy metals toxicity (Lead, Cadmium, Mercury and Arsenic). Recent studies have shown that a deficiency in zinc, calcium or iron can lead to greater absorption and toxicity of Cadmium, which is one of the most toxic environmental and industrial pollutants, which adversely affects biological systems in various ways $[2,3,4]$. Many studies have shown that exposure to cadmium causes an accumulation of this metal in the brain due to its ability to penetrate into the Blood Brain Barrier. In this way, this neurotoxic is able to induce neurological disturbances, changes in normal neurochemistry of the brain and neurocognitive disorders, such as alteration in memory, attention, psychomotor and visuomotor functions, and alterations in cholinergic neurotransmission $[5,6]$. Numerous animal studies have demonstrated behavioral disorders, morphological, and biochemical changes in the brain in Cd-exposed animals. In clinical and epidemiological studies, cognitive function disabilities have also been observed in Cd-exposed populations $[7,8,9,10]$.

The aim of this study was to investigate the neuroprotective effect of Lepiudum sativum L. on modulation of toxic effects induced by cadmium.

\section{Materials and Methods}

\subsection{Animals and housing}

Twenty-one adults female wistar rats (weighting $155.95 \pm 3.99 \mathrm{~g}, 3$ months old) were obtained from the breeding center of Faculty of Science, Ibn Tofail

*Corresponding author: soumia.day@gmail.com 
University. They were housed in scientific cages and kept under constant temperature of $22 \pm 2^{\circ} \mathrm{C}$, using a $12 \mathrm{~h}$ light/12 h dark cycle (light on at 6am), with free access to food and water (standard diet). All experimental procedures were performed according to the National Institutes of Health (NIH) Guide for the Care and Use of Laboratory Animals. All efforts were made to minimize any animal suffering.

\subsection{Lepidium sativum L. extraction}

Lepidium sativum $L$ (LS) seeds were purchased from a local market in Kenitra, Morocco.

The aqueous extract was prepared according to the standardized manner used in Morocco (decoction), by boiling $0.5 \mathrm{~g}$ of powdered seeds of Lepidium sativum $L$ in $10 \mathrm{ml}$ of distilled water for $10 \mathrm{~min}$ and left for $15 \mathrm{~min}$ to infuse. Thereafter, the extract was cooled and filtered to remove particulate matter. The filtrate was lyophilized and the desired dose (milligram of lyophilized aqueous LS extract per kilogram body weight) was then prepared and reconstituted in $10 \mathrm{ml}$ of distilled water per kilogram of body weight just before oral gavage [11]. Lyophilization has been made at the Center of Analysis, Expertise, Technology Transfer and Incubation of Ibn Tofail University.

\subsection{Experimental design}

The study was carried out during 2 months, on 21 female Wistar rats. They were divided into 3 groups $(n=7)$ :

- Control group(T): were received a distilled water orally $1 \mathrm{ml} / 100 \mathrm{~g}$ of body weight;

- Treated group $\left(\mathbf{C d C l}_{2}\right)$ : were received oral administration dose of $\mathrm{CdCl}_{2}$ at $10 \mathrm{mg} / \mathrm{kg}$;

- Treated group $\left(\mathbf{C d C l}_{2}+\mathbf{L S}\right)$ : were received $\mathrm{CdCl}_{2}(10 \mathrm{mg} / \mathrm{kg})$ and the aqueous extract of Lepidium sativum L. $(20 \mathrm{mg} / \mathrm{kg})$ orally.

\subsection{Behavioral assessment}

\subsubsection{Object recognition test}

The object recognition test is a specific behavioral test of memory and learning in rats. This test makes it possible to evaluate non-spatial episodic memory [12]. Based on the fact that rodents naturally prefer the new object in relation to the familiar object. The apparatus consisted of an open field in a cubic form $(50 \times 50 \times 50 \mathrm{~cm})$; whose interior is painted black and illuminated by a light source $1 \mathrm{~m}$ above the box and controlled by a camera linked to the computer to record the behavior. The objects to be discriminated were made of solid metal, and their weight ensured that the rats could not displace them. The interior of the test and the objects were cleaned with alcohol to remove the smell of the rats after each passage in the box.

The object recognition test is completed over 3 days (habituation session, acquisition session).
-During the habituation session, the rat is allowed to explore freely the box for $5 \mathrm{~min}$.

-The next day "the acquisition session" the animal is allowed to explore 2 identical objects (A) the time spent exploring each object was measured for $5 \mathrm{~min}$. After a retention period of $2 \mathrm{H}$ (examine short-term memory), the animal is allowed to explore freely two different objects (A and $\mathrm{B}$ ) one of the habituation objects $(\mathrm{A})$ is replaced with a novel object (B).

-During the third day (examine long-term memory) the animal is allowed to explore two different objects (A and C). The time spent exploring the familiar object (A) and the novel object (C) was recorded for $5 \mathrm{~min}[12,13]$.

\subsection{Biochemical evaluation}

\subsubsection{Determination of Acetylcholinesterase (AChE) activity}

Cholinergic dysfunction was assessed by the determination of Acetylcholinesterase activity in the cortex, hippocampus, and cerebellum.

$24 \mathrm{~h}$ after behavioral test rats were sacrificed by decapitation. Brain was carefully removed and chilled on ice filled glass culture plates. All the meninges and blood vessels were removed carefully before dissection. Three regions were separated: cortex, hippocampus and cerebellum. The dissection of the brain was performed as follows:

First the cerebellum is separated from the rhombencephalon and the rest of the brain by a transverse section. Then the frontal cortex is carefully removed by another transverse section. The midbrain is gently separated from the remaining part of the brain, the hippocampus is then dissected. Samples of brain correspondent to cortex, hippocampus and cerebellum areas are removed and homogenized in buffer Tris/ $\mathrm{HCl}$ $(50 \mathrm{mmol} / \mathrm{L}, \mathrm{pH} 7.3)$ and Sucrose $(0.32 \mathrm{~mol} / \mathrm{L})$. The homogenate is centrifuged at $1000 \mathrm{xg}$ for $15 \mathrm{~min}$ at $4^{\circ} \mathrm{C}$. AChE activity is assayed according to Elman method [14], using acetylthiocholine iodide as a substrate. Reaction mixture contained $100 \mu \mathrm{L}$ of supernatant, $4 \mu \mathrm{L}$ of substrate $(75 \mathrm{mM}), 15 \mu \mathrm{L}$ of Dithiobisnitrobenzoic acid (DTNB as Ellman's reagent, $100 \mathrm{mM}$ ) and $3.0 \mathrm{ml}$ of phosphate buffer ( $\mathrm{pH} 8.0)$. The rate of Acetylthiocholine iodide hydrolysis is measured at $412 \mathrm{~nm}$ in spectrophotometer for $10 \mathrm{~min}$. Brain AChE is expresses in percent of inhibition from control [15].

\section{Results}

\subsection{Behavioral assessment}

\subsubsection{Object recognition test}

The control group displayed an increase in recognition index, as the exposure to subchronic intoxication of $\mathrm{CdCl}_{2}$ $(10 \mathrm{mg} / \mathrm{kg})$ causes a significant decrease in the recognition index $(\mathrm{p}<0.01)$ compared to control group. 
Whereas, the aqueous extract of Lepidiumsativum $L$ attenuated the effect of $\mathrm{CdCl}_{2}$ in significant way $(\mathrm{p}<0.01)$ compared to cadmium treated rats. This attenuation in the same degree as the control rats.

A significant decrease in the recognition index of LTM $(p<0.05)$ in cadmium exposure group compared to control group. However, there is no significant differences in the recognition index of LTM in rats treated with the aqueous extract of Lepidium sativum L. as compared to cadmium exposure rats and control rats (fig.1).

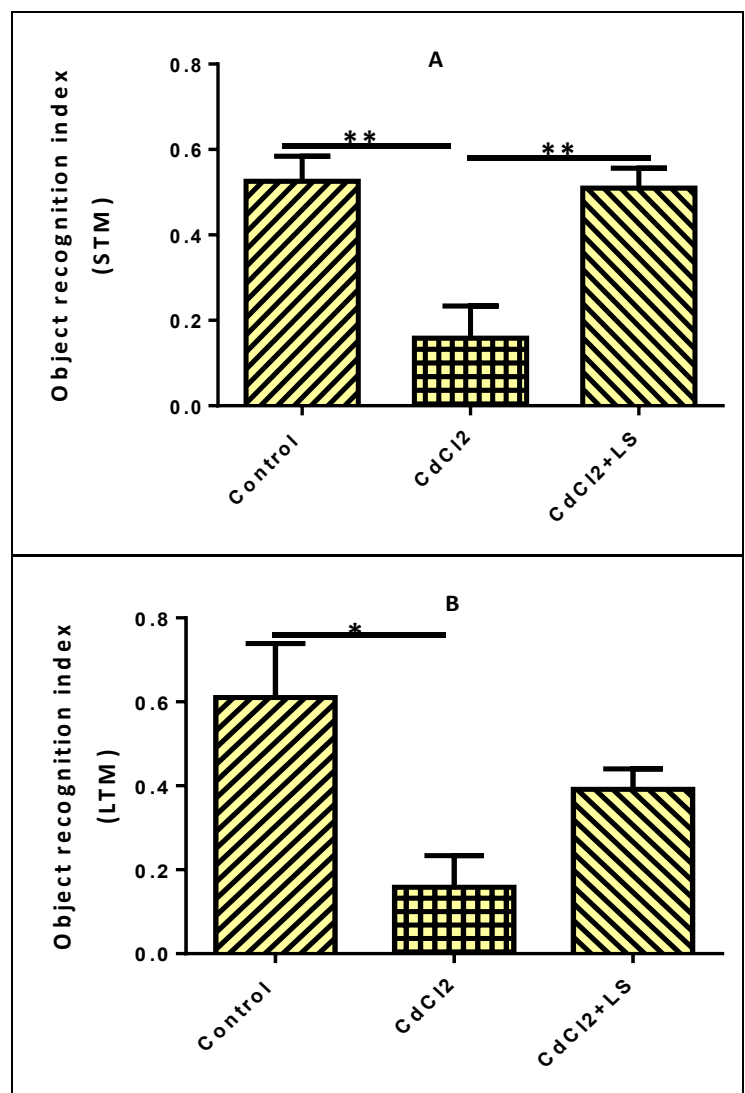

Fig. 1: Effect of cadmium exposure at a dose of $10 \mathrm{mg} / \mathrm{kg}$ (subchronic intoxication) and the aqueous extract of Lepidiumsativum L $(20 \mathrm{mg} / \mathrm{kg})$ on A. The recognition index at $2 \mathrm{~h}$ after training B. the recognition index $24 \mathrm{~h}$ after training (LTM). The results are expressed as Mean \pm SEM. The significance level is $0.05 .{ }^{*} \mathrm{p}<0.05,{ }^{*} \mathrm{p}<0.01,{ }^{* * *} \mathrm{p}<0.001$ ( One Way ANOVA and post hoc multiple comparisons).

\subsection{Neurochemical analysis}

\subsubsection{Acetylcholinesterase (AChE) activity}

Figure 2 shows the enzymatic activity of AChE in the brain areas. The two treatment groups displayed highly significant increase in AChE inhibition rate in the cortex , hippocampus, and cerebellum $(\mathbf{p}<\mathbf{0 . 0 0 1})$ compared to control group.

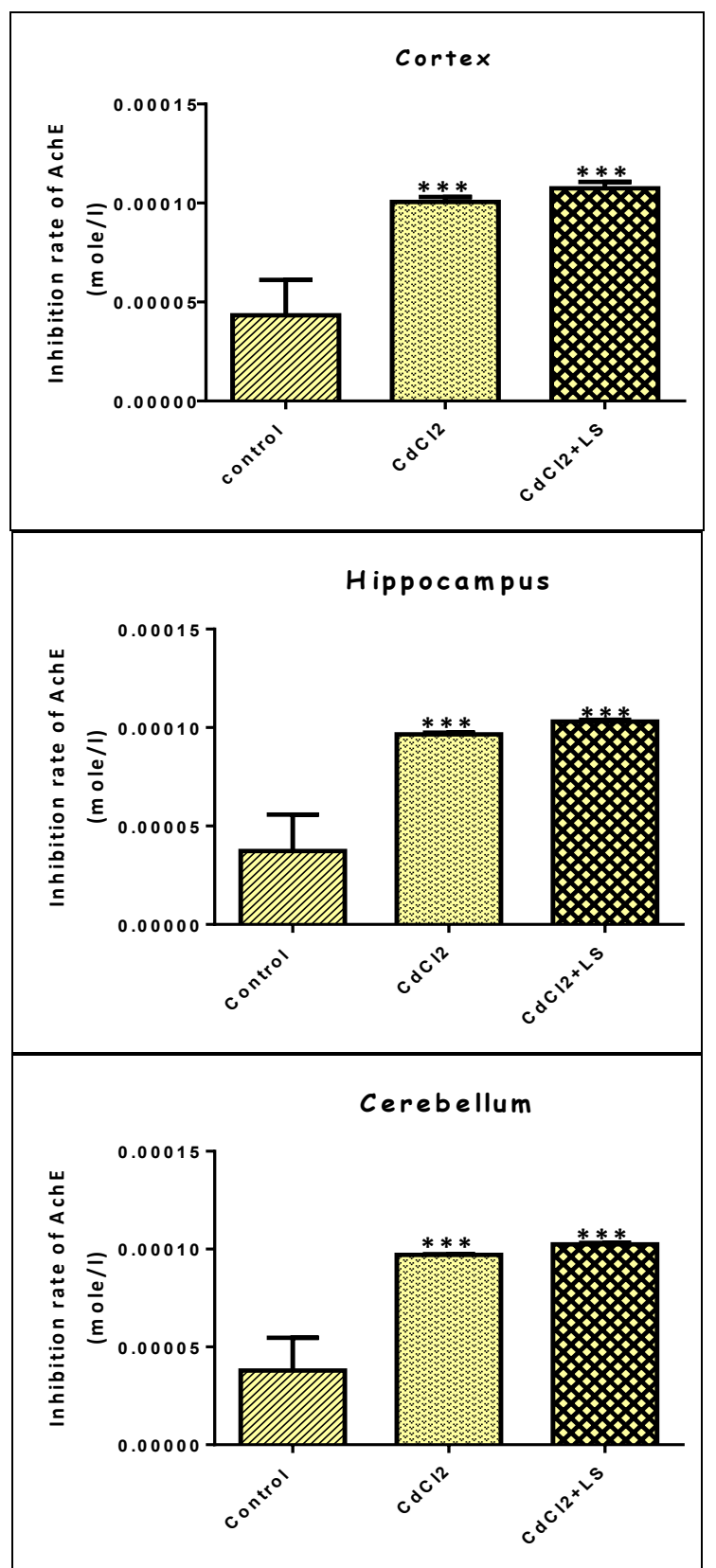

Fig. 2: Effect of $\mathrm{CdCl}_{2}$ subchronic toxicity and the administration of the aqueous extract of Lepidium sativum $L$ on inhibition rate of $\mathrm{AChE}$ in the different brain structures (cortex, hippocampus, and cerebellum).The results are expressed as Mean \pm SEM. The significance level is 0.05 . ${ }^{*} \mathrm{p}<0.05,{ }^{* *} \mathrm{p}<$ $0.01,{ }^{* * *} \mathrm{p}<0.001$

\section{Discussion}

The main objective of this study was to determine the effects of subchronic exposure to $\mathrm{CdCl}_{2}(10 \mathrm{mg} / \mathrm{kg})$ and the aqueous extract of Lepidium sativum $L(20 \mathrm{mg} / \mathrm{kg})$ on object recognition memory and Acetylcholinesterase (AChE) activity in the cortex, hippocampus and cerebellum.

Exposure to Cadmium is able to induce disturbance in several organs, following either acute or chronic exposure. This metal can induce abnormality in neuronal function and it can produce impairment of neurobehavioral status such as alterations in memory. 
Hippocampus cortex and cerebellum areas of brain are implicated in memory processes. These regions play an important role in everyday memory formation for facts and habituations. In the present study, daily exposure to Cadmium for a period of 2 months (subchronic toxicity) showed that rats exposed to a dose of $10 \mathrm{mg} / \mathrm{kg}$ of $\mathrm{CdCl}_{2}$ exhibited an impaired in recognition index during evaluating the short and long term memory compared to control group. These results suggest that animal recognition memory was impaired by the chronic $\mathrm{CdCl}_{2}$ administration. In accordance with our results, several studies demonstrate that $\mathrm{CdCl}_{2}$ causes impaired learning and memory in rats [16].

Goncalves J. et al. in 2010 showed that rats exposed to Cadmium for 30 days displayed inhibition of acetylcholinesterase activity, by acting on the active sites of the enzyme or by its deactivation which leads to lesions of brain structures involved in the memorization processes. Our study shows that the co-administration of the aqueous extract of Lepidium sativum $L$. leads to improvement of recognition memory. This improvement of the memory could be explained by the action of the plant constituents on the cholinergic system [17], However, Lepidium sativum $L$. does not seem to have a significant impact on the modulation of AChE activity

The authors thank Sara Susan (Centre for Interdisciplinary Research in Biology Collège de France, Paris, France) for her help in preparing the manuscript.

\section{References}

1. D. Manohar, G. L. Viswanatha, S. Nagesh, V. Jain, , H. N. Shivaprasad,. Enthopharmacology of Lepidium Sativum Linn (Brassicaceae): A Review, 2(1), 8. (2012)

2. P.G. Reeves, R.L. Chaney, Marginal nutritional status of zinc, iron, and calcium increases cadmium retention in the duodenum and other organs of rats fed rice-based diets. Environ. Res, 96, 311-322. (2004).

3. S.E. Larsson, M. Piscator, Effect of cadmium on skeletal tissue in normal and calcium-deficient rats. Isr. J. Med. Sci.7, 495-498. (1971).

4. T.A. Hammad, M. Sexton, P. Langenberg. Relationship between blood lead and dietary iron intake in preschool children: A cross-sectional study. Ann. Epidemiol.6,30-33. (1996).

5. A. Shukla, G.S Shukla, R.C. Srimal, Cadmiuminduced alterations in blood-brain barrier permeability and its possible correlation with decreased microvessel antioxidant potential in rat. Hum. Exp. Toxicol, 15, 400-405. (1996).

6. J. Goncalves, A.M. Fiorenza, R.M. Spanevello, C.M. Mazzanti, G.V. Bochi, F.G. Antes, et al. Nacetylcysteine prevents memory deficits, the decrease in acetylcholinesterase activity and oxidative stress in rats exposed to cadmium. ChemBiol Interact, 186, 53-60. (2010).
7. E.S.E De Castro, H. Ferreira, M. Cunha, C. Bulcao, C. Sarmento, I. De Oliveira, et al. Effect of central acute administration of cadmium on drinking behavior. Pharmacology Biochemistry and Behavior, 53: 687-693. (1996).

8. W.S. Webster, and A.A. Valois, The toxic effects of cadmium on the neonatal mouse CNS. Journal of Neuropathology and Experimental Neurology, 40: 247-257. (1981).

9. M. Marlowe, J. Errera, and J. Jacobs, Increased lead and cadmium burdens among mentally retarded children and children with borderline intelligence. American Journal of Mental Deficiency , 87: 477-483. (1983).

10. M.K Viaene, R. Masschelein, J. Leeders, M.De. Groof, L.J.V.C.Swerts, H.A. Roels, Neurobehavioural effects of occupational exposure to cadmium: a cross sectional epidemiological study. Occup. Environ. Med, 57, 19-27. (2000).

11. M.Eddouks, M. Maghrani, N.A. Zeggwagh, J. B. \& Michel, Study of the hypoglycaemic activity of Lepidium sativum L. aqueous extract in normal and diabetic rats. Journal of Ethnopharmacology, 97(2), 391-395. (2005).

12. F.Z. Azzaoui,. Le plomb et l'aluminium: Etude d'impact sur la santé et évaluation du potentiel chélateur de certaines plantes médicinales. Thèse. Université Ibn Tofail, Kenitra, Maroc. (2009)

13. A. Ennaceur, J. Delacour, A new one-trial test for neurobiologicalstudies of memory in rats. 1 . Behavioral data. BehavBrainRes 31,47-59. (1988).

14. G.L. Ellman, K.D. Courtney, , V.Jr. Andres, R.M. Feather-Stone A new and rapid colorimetric determination of acetylcholinesterase activity. Biochem Pharmacol, 7:88-95. (1961).

15. F.Z,Azzaoui, H.Hami, M. El-Hioui, S. Boulbaroud and A. Ahami .Attempt at the Determination of Aluminum Nitrate LD50 and the Study of Its Neurotoxicological Effect in Wistar Rat, Biology and Medicine, Vol. 4, pp. 89-94. (2012).

16. S. Haider, S. Saleem, T. Perveen, S. Tabassum, Z. Batool, S. Sadir, S. Madiha, Age-related learning and memory deficits in rats: role of altered brain neurotransmitters, acetylcholinesterase activity and changes in antioxidant defense system. $A G E, 36(3)$. (2014).

17. J. Micheau, A. MarighettoAcetylcholine and memory: A long, complex and chaotic but still living relationship. Behavioural Brain Research, 221(2), 424-429., (2011). 